Digital Press Social Sciences and Humanities

Smart Airport Model Implementation as A Tourist Attraction in West Java International Airport Kertajati

Faisal, Amelia Nur Fatihah, Sandra Nisrina Aprilia and Wiliyanda

Proceeding of Indonesia Heritage Tourism Forum 2019 (IHTF 2019)

Dewi Pratika Ayu Dhira Pradati (eds) 


\title{
Smart Airport Model Implementation as A Tourist Attraction in West Java International Airport Kertajati
}

\author{
Faisal*, Amelia Nur Fatihah, Sandra Nisrina Aprilia, Wiliyanda
}

NHI Bandung Institute of Tourism, Bandung, Indonesia

*e-mail: sal_bugisbandung2015@yahoo.com

\begin{abstract}
West Java International Airport is located in Majalengka Regency, West Java. BIJB Kertajati Airport received an award in the Smart Airport category at the Airport Award event. The airport will become a tourist attraction with a minimal area to hold passengers before their flight. This study aims to find out how the implementation of the smart airport model as a tourist attraction at the West Java International Airport (BIJB) Kertajati. The study used descriptive qualitative methods. The data analysis technique used was the triangulation. The process of data collection was done through an interview process with airport managers, passengers, and the public through direct observation. Based on the results of the analysis, it can be seen that smart airport is an innovation to simplify and make passengers feel a new experience and can meet the needs of passengers for entertainment or attraction while waiting for departure time. BIJB also has an Aero city area in which there will be a playground such as a theme park, accommodation, and others. With all the attractions in Aero city, BIJB's smart airport can be a tourist attraction that gives new experiences and attracts visitors to come.
\end{abstract}

\section{Keywords}

personalized services, smart airport, tourist attraction, visitor experience

\section{Introduction}

Industry 4.0 is the fourth industrial revolution, with systems related to embedded systems, cyber-physical systems (CPS), smart factories, Internet of Things (IoT), and Internet of Services (IoS) (Raj \& Raman, 2017). In Indonesia, Tourism 4.0 emerged along with the industrial revolution 4.0, according to the Minister of Tourism of the Republic of Indonesia Arief Yahya, Tourism 4.0 created a seamless and personalized traveling experience aimed at millennial tourists who have used technology. The series of millennial tourist trips, one of which is activities while at the airport, certainly makes an airport need to grow and improve its operations by utilizing technology. This causes the airport to experience development towards the concept of "smart" which leads to an increasingly effective and efficient operational system (Anagnostopoulou, 2017).

The smart airport is an airport that utilizes network response capabilities supported by data by providing a better travel experience for tourists and aims to ensure a higher level of security for the safety of passengers and operators (Anagnostopoulou, 2017). The six Smart Airport indicators are Personalized Services, Smart Services, Smart Safety, and Security, Ground Staff Mobility, Asset Tracking, and World Class Shared Services Facility (Anagnostopoulou, 2017; European Union Agency For Network And Information Security, 2016; Popa, Popa, \& Codescu, 2016).

In the tourism sector, airports are access to a tourist destination. This access is one of the three factors of the Tourism Ecosystem program echoed by the Ministry of Tourism of the Republic of Indonesia, namely accessibility, amenities, and attractions (Angkasapura II, 2019). However, along with its development, currently, the airport indirectly has an attraction for passengers. When associated with the tourism ecosystem concept, which includes accessibility, the airport can be a "new attraction in special space" (Angkasa Pura II, 2019). Attractions are events or creations in the natural or man-made environment that motivate people to come, which include events such as festivals, meetings, sports competitions, etc., while including creations such as scenery, climate, hot springs, flora or fauna, buildings or works other architecture, history, artwork, entertainment, etc. In four smart airport projects in the future, namely passenger transport, check-in, passenger luggage, security control, boarding, passenger communication, 
and tracking, retail, and leisure, in leisure projects, the airport will become a resort-style destination with a minimal area to hold passengers before the flight. Smart airports that produce artificial tourist attractions will make prospective passengers prefer to fly at the airport. Smart airports that produce tourist attractions will make prospective passengers prefer to fly at the airport. Like Changi Airport, which in addition has implemented the implementation of the smart airport in the form of self-check-in, self-immigration, selfdrop bag, self-boarding gate, smart parking services, the airport also offers tourist facilities and attractions such as the newest one is Jewel Changi Airport with a vision to be a destination that can meet the increasing needs of tourists to find impressive trips. Seven indicators of artificial tourist attractions are Market Share, Tourist Attractions and Activities, Accessibility, Accommodation, Infrastructure, Facilities and Services, and Institutional Elements (Swarbrooke, 2002). Based on the research background, the research focus is as follows:

1. How is the smart airport model implemented at Kertajati West Java International Airport (BIJB)?

2. How is the smart airport model used as a tourist attraction?

\section{Methods}

This study uses descriptive qualitative methods. This descriptive qualitative method is used by researchers to describe clearly and deeply about the implementation of the smart airport model at West Java International Airport (BIJB) Kertajati as a tourist attraction. In this study, data collection was done by interviewing the airport manager. Observations in this study were conducted to see the suitability of what the airport had explained to the reality in the field.

Data analysis in this study uses data analysis of the Miles and Hubermen's model, data analysis is carried out when data collection takes place and after data collection is completed within a certain period of time (Sugiyono, 2012). The several stages in the data analysis process, including data reduction, data presentation, and conclusion drawing. Then the researchers also used a triangulation technique where researchers combined data that had been obtained from various sources and techniques of data collection. In testing the validity of the data, it consists of the credibility test process (internal validity), transferability (external validity), dependability (reliability), and confirmability (objectivity).

\section{Finding and Discussion}

\subsection{Implementation of the Smart Airport Model in West Java International Airport (BIJB) Kertajati}

\subsubsection{Personalized Services}

Personalized service is an aspect in which there is an indicator, namely seamless and world-class passenger experience, in the form of automatic tools or machines that can be used independently by passengers in every process at the airport, such as self-check-in machines, self-drop bags, self-immigration, and the selfboarding gate, which is able to provide a special experience for passengers. Of the four machines, only two engines are available at BIJB, namely self-check-in and self-boarding gate which can only be used in the domestic departure area, in the international departure area, the self-check-in machine is available, but cannot be used because there is no international flight at BIJB.

Even though the self-check-in engine in the domestic departure area can be used properly, not many passengers use the engine, because the passengers do not know the location of the self-check-in machine. In addition, a check-in counter that does not line up causes passengers to check-in via a counter. However, these passengers still use other service engines, namely the self-boarding gate engine, so that passengers still feel the world-class passenger experience.

\subsubsection{Smart Services}

Smart Services consists of several indicators, namely automatic parking payment machines, parking, and digital advertising booking systems. BIJB has several features in its application such as a parking booking system, only this parking management system has not been activated for that, because the number is still small. 
Digital advertising at BIJB has several Videotron points. There are only three Videotron live because some points are under construction and passengers who haven't arrived much, besides that BIJB also has a Flight Information Display System (FIDS) that can see departure schedules, films, texts, and photos. This FIDS is working so that passengers can see their departure schedule.

\subsubsection{Smart Safety and Security}

Smart safety and security is a service of security and safety of passengers, this aspect consists of several indicators where smart CCTV in BIJB already has several functions of CCTV that are executed, such as face recognition, lost items, lost items are intended if the passenger saves the bag and lost, later this CCTV will give a beep warning. In this aspect, BIJB has not yet implemented a full-body 3D scanner engine, but still uses 2D x-ray machines.

\subsubsection{Ground Staff Mobility}

BIJB has a digitization which starts from the operational attendance process, then official licenses that have used the fingerprint absence system, which will later be approved through a special website for BIJB employees. In addition, BIJB already has a GSuite account or Gmail Suite specifically for corporate, wherein this GSuite, employees can hold conferences, send messages, save and create documents and documents that can be made together in different gadgets. In the aspect of real-time collaboration, this system called the AOCC (Airport Operation Control Center) is an overall airport control center system. This system can see the number of passengers, number of visitors, number of flights, the amount of money entered, and the number of tenants.

\subsubsection{Asset Tracking}

In this case, BIJB already has a baggage tracking contained in the application but no one has used it. BIJB uses two things, the first is the semi-automatic Baggage Handling System (BHS) and the second is the Baggage Reconciliation System (BRS). BHS in BIJB is said to be semi-automatic because the separation of the baggage is not based on the route but based on suspicious baggage or not, there is only one BHS in the BIJB. BRS is a device where every point uses a special scanner that can read a barcode, the result is an information about the existence of baggage from each passenger that can be accessed through the BIJB Mobile application

\subsubsection{World Class Shared Service Facilities}

In this case, BIJB has a BIJB Mobile application that can be downloaded by anyone who has an Android smartphone. BIJB Mobile can facilitate and assist passengers starting from booking tickets, until arriving at BIJB. In BIJB Mobile there are features such as alerts, add my flight, baggage tracker and BIJB already has an entertainment platform, which later passengers can watch the latest movies that can be accessed for free.

\subsection{Smart Airport as a Tourist Attraction}

\subsubsection{Market Share}

The domestic market share targeted by BIJB has been achieved and the majority of BIJB passengers are Cirebon people, but the overall number is still relatively small due to a number of factors, such as airplane ticket prices which have recently surged. For the international market, until now there has not been yet, because the new $3000 \mathrm{~m}$ BIJB runaway will be completed in March 2019 and the new permit will be issued in May 2019, previously the BIJB runaway was built only as long as $2500 \mathrm{~m}$. Then for local visitors, BIJB has enlivened the events held, and also outside of these events local visitors are also crowded because they are curious about the new airports in their neighborhood and also around Kertajati, not many tourist attractions that can be visited by the people so they appreciate This BIJB is an interesting place to visit.

\subsubsection{Tourist Attractions and Activities}

Currently, BIJB has iconic photo spots that are usually used as passengers, come to BIJB, take a photo there, where the photo spot is a Mega Mendung batik motif that appears with a pink base color, but the photo spot is only on the third floor so that only passengers can access the location, for the general public who only come to see they usually capture themselves in front of the writing of the West Java International Airport. In addition, there is also a peacock garden where there is a peacock that symbolizes BIJB which means welcome, the peacock park can be accessed by the public. BIJB also has a place to read books with various 
categories of books for passengers who want to read or are tired of waiting for their flight to read a book first.

There is a virtual reality paragliding that can be used to eliminate the boredom of passengers, but for virtual reality (VR) paragliding has not yet functioned because BIJB is still waiting for crowded passengers first, BIJB also provides augmented reality (AR) that can be accessed on Android-based smartphones or IOS. BIJB in the future will make tourist attractions with the concept of education, where the purpose of this is that passengers who come to BIJB can get educated while having fun.

\subsubsection{Accessibility}

To get to BIJB, passengers and visitors can only use travel shuttle from Bandung, Cirebon, Kuningan, Purwakarta, and Indramayu. Then for the Aerocity region, there will be LRT (Light Rail Transit), BRT (Bus Rapid Transit), and MPS / MPLS. This mode of transportation is the same as the MRT (Mass Rail Transit), the difference is only one car.

\subsubsection{Accommodation}

In the BIJB and surrounding areas, there are no hotels for passengers who want or need to spend the night around BIJB. The absence of this accommodation is due to investors who still see the condition of BIJB, for now, that the passengers at BIJB are still very few. This is also related to demand and supply, with the condition of the passengers being few, then most of the passengers flying through Kertajati domiciled in Majalengka, Cirebon and surrounding areas cause a lack of demand for accommodation so that the offer will be directly proportional.

\subsubsection{Infrastructure}

The difficulty of access to BIJB is one reason why prospective passengers think twice about using air transportation through BIJB. For now, it is still under construction, namely the Cisumdawu toll road, the toll road connects Cileunyi, Sumedang, and Dawuan, the Cisumdawu toll road is planned to be completed in 2020. Not only in terms of the ease of access to BIJB, when the Kertajati area was already in the infrastructure, but it also was still not good because the inconsistency of the routes in the Kertajati area and the lighting of the roads were still very lacking, according to the researchers' observations.

\subsubsection{Tourist Facilities and Services}

BIJB has several facilities and services, namely toilets that are disability-friendly and equipped with child protection seats, nursing rooms equipped with handwashing places, places of worship, bathrooms, and seatings equipped with cell phone outlets and battery chargers and priority seats which is adequate and meets the needs of passengers and visitors. Other facilities available at BIJB are quiet rooms in the departure lounge.

\subsubsection{Institution Element}

Currently, BIJB has collaborated with various parties, including the information technology section with Dell, Sony, BOSS, Honeywell, TAV Turkey, and MCO, then collaborated with Changi Airport as a consultant, and collaborated with the Airport in Medina as the sister airport, where this can have a positive impact on BIJB. In addition, the response of the people affected by BIJB development received and supported the existence of BIJB.

\section{Conclusion}

\subsection{Conclusion}

The smart airport is an innovation to simplify and make passengers feel a new experience (Fattah, Lock, Buller, \& Kirby, 2009). Not only from the sophistication of technology and convenience, but this smart airport model is even wider, as the airport has an integrated system namely Airport Operation Control Center (AOCC), this AOCC system can monitor and control all activities and areas within the airport. Then assisted by the technology used at the airport such as self-check-in, self-boarding gate, semi-self-bag drop, $\mathrm{Wi}-\mathrm{Fi}$, website, and mobile application, where the data collected is in the form of big data and the data is processed which results in the form of decisions required by passengers airport side. 
The smart airport can be seen from how an airport can meet the needs of its passengers. Passengers need entertainment or attraction while waiting for the departure time. BIJB's plan in the future will have a place like a rooftop café, a cinema that can be accessed by passengers and visitors and the BIJB has an aero city area in which there will be a playground such as a theme park, accommodation, and others. With all the attractions in the aero city, BIJB's smart airport can be made an artificial tourist attraction that gives new experiences and attracts visitors to come.

\subsection{Implication}

This research can be used as an evaluation material for the BIJB to increase awareness of the existence of airports that have large capital to be made artificial tourist attractions that can attract prospective passengers or visitors.

\subsection{Suggestion}

1. There needs to be a sign of the location of the self-service tools so that passengers can find out and use the service. In addition, it would be better if the airport manager provides education about smart airports to people who cannot yet operate services such as self-service that is already available at BIJB so that passengers can use it.

2. In making BIJB smart airport as a tourist attraction, it is necessary to have tourist attractions in BIJB which can be a pull factor so that passengers are more interested in coming to BIJB, such as increasing events, display buildings (museums), and plans to build cinemas. Immediately run.

3. It is expected that further research will discuss more about the potential of any tourist attractions that can be presented at BIJB.

\section{References}

Anagnostopoulou, A. A. (2017). Improving Security And Cyber Resilience In Smart Airport MSc Thesis. Athens: Athens University of Economics and Business.

Angkasapura II. (2019). Digital Travel Destination Starting from Airport. Retrieved from https://www.angkasapura2.co.id/en/news/event/pers/246-destinasi-wisata-digital-bermula-dari-bandara

European Union Agency For Network And Information Security. (2016). Securing Smart Air-ports Enisa. Retrieved from European Union Agency Fro Cybersecurity website: https://www.enisa.europa.eu/publications/securing-smart-airports

Fattah, A., Lock, H., Buller, W., \& Kirby, S. (2009). Smart Airports : Transforming Passenger Experience To Thrive in the New Economy. Retrieved from Cisco Internet Business Solution Group website: https://www.cisco.com/c/dam/en_us/about/ac79/docs/pov/Passenger_Exp_POV_0720aFINAL.pdf

Popa, P. E., Popa, A., \& Codescu, P. M. (2016). Smart Airport Structure and Element. Buletinul AGIR, Suppliment, 3, 6-7. Retrieved from http://www.agir.ro/buletine/2812.pdf

Raj, P., \& Raman, A. C. (2017). The Internet of Things Enabling: Technologies, Platforms, and Use Cases. Boca Raton: Taylor \& Francis Group, LLC.

Sugiyono, P. D. (2012). Metode Penelitian Kuantitatif, Kualitatif dan Kombinasi (Mixed Methods). Bandung: Alfabeta.

Swarbrooke, J. (2002). The Development and Management of Visitor Attractions. London: Reed Educational and Professional Publishing Ltd. 